\title{
ESTUDO DE CASO DE INTERPRETATIVISMO SIMBÓLICO NA ÁREA DE P\&D E SUA INFLUENNCIA SOBRE O PROCESSO DECISÓRIO EM EXTERNALIZAÇÃO DE SUAS ATIVIDADES
}

Data de submissão: 26/12/2013 Aceite: 16/07/2016

Dusan Schreiber ${ }^{1}$

\section{RESUMO}

O universo organizacional, como recorte do tecido social, evidencia características que o tornam complexo e multifacetado. Os valores e imagens, bem como os mitos, as narrativas, os rituais e rotinas, as regras, entre outros, precisam ser interpretadas no tocante ao seu conteúdo simbólico, por todos que fazem parte e compartilham o ambiente organizacional. O presente artigo analisa o caso da empresa BETA, de base tecnológica, localizada na região metropolitana de Porto Alegre, visando compreender a rede das relações sociais subjacentes à interpretação simbólica das pessoas alocadas na unidade de P\&D, bem como identificar se e como essa interpretação pode influenciar a decisão sobre a forma de realizar as atividades de pesquisa tecnológica. O estudo se justifica na medida em que a inovação, tanto tecnológica como organizacional, deixou de ser um modismo, para ocupar um lugar de destaque dentro das organizações. Com a abertura dos mercados e a sofisticação do padrão de exigência de consumidores, tanto no mercado interno como no exterior, a diferenciação passou a ser palavra de ordem e a inovação, uma necessidade. Dentro da inovação tecnológica, as atividades de pesquisa e desenvolvimento são consideradas essenciais e têm merecido, cada vez mais, a atenção de pesquisadores. Considerada tradicionalmente uma área eminentemente técnica, com foco em concepção de soluções tecnologicamente e comercialmente viáveis, o setor de P\&D assumiu novas atribuições, o que implicou a alteração do perfil dos técnicos que passam a interagir mais com as outras unidades organizacionais. Esse processo implica a ampliação do universo simbólico do grupo de técnicos da referida área, com inclusão, no seu repertório, de novos valores e critérios, que são considerados no processo decisório.

Palavras-chave: Interpretativismo simbólico, Área de P\&D, Externalização de atividades.

\footnotetext{
1 Possui graduação em Administração de Empresas pela Universidade do Vale do Rio dos Sinos, UNISINOS, graduação em Licenciatura pela Universidade Feevale, FEEVALE, mestrado em Administração pela UNISINOS e doutorado em Administração pela Universidade Federal do Rio Grande do Sul, UFRGS. Novo Hamburgo - RS. Brasil.
}

E-mail: dusan@feevale.br 


\section{INTRODUÇÃO}

As organizações se deparam, atualmente, com o contexto caracterizado pelo alto grau de complexidade. Multifacetado e multidirecional, tanto nas relações internas como externas, o contexto dentro do qual a organização está inserida dificulta a concepção da forma de atuar com vista a assegurar sua permanência no mercado. Destarte está se tornando mandatório, para as organizações, o desenvolvimento de um conjunto de competências que possam constituir a fonte de diferenciação no segmento no qual elas atuam. Entre essas competências, destacam-se a capacidade de inovar produtos e processos com o objetivo de atender às expectativas do mercado consumidor no tocante a design, qualidade, funcionalidade e preço. Além desses atributos, considera-se essencial que a organização realize a inovação de produtos em períodos temporais cada vez mais curtos (TIDD; BESSANT; PAVITT, 1997; CHRISTENSEN, 2002; KIM; MAUBORGNE, 2005; PLENTZ; BERNARDES; FRAGA, 2015).

Essa especificidade do processo de inovação impacta diretamente na capacidade da organização de inovar em processos de gestão, o que propicia a reflexão sobre novas formas de organizar os recursos e tomar decisões à luz da complexidade presente no ambiente no qual a organização está inserida (WHEELER, 2003; SASSENBURG; BOSS; RABUNG, 2005). Percebe-se que a competência em organizar os recursos, de forma inovadora, constitui a base para a construção do diferencial competitivo das organizações, bem como norteia o processo decisório com vista à otimização dos recursos internos disponíveis (KAY, 1996; MILLER; MORRIS, 1998; GHEMAWAT, 2002).

Uma das áreas organizacionais que estão diretamente vinculadas à inovação de produtos é o setor de Pesquisa e Desenvolvimento (P\&D), com a concepção original fundamentada em critérios objetivos, normativos e técnicos, com vista à realização das atividades operacionais de pesquisa básica e aplicada, sempre voltada para a sustentabilidade econômica (WESTWOOD; SEKINE, 1988; STOKES, 2005). Ao longo do tempo, houve ampliação da função de P\&D, com a inclusão de "uso" ou "utilidade" transcendendo a mera viabilidade econômica e permitindo à organização visualizar novos benefícios das atividades vinculadas a P\&D (STOKES, 2005; O'CONNOR; AYERS, 2005). Trata-se de novas competências e conhecimentos, decorrentes das atividades de pesquisa e desenvolvimento realizadas na interação com as demais áreas e unidades organizacionais (MCNULTY; WHITTINGTON, 1992), configurando um conceito interdisciplinar da área de $P \& D$, em que cada uma das unidades organizacionais pode contribuir para o desenvolvimento de novos produtos e processos operacionais.

Ao mesmo tempo que essa interdisciplinaridade da área de P\&D possibilita a construção de um diferencial competitivo ímpar, por constituir um ativo raro e de difícil imitação pelos competidores (BARNEY, 1991; CHANDLER, 1992; KAY, 1996; BOERNER; MACHER; TEECE, 2001), a maior intensidade na interação com as demais unidades organizacionais implica alteração do perfil funcional originalmente concebido. Trata-se de maior influência das variáveis subjetivas sobre o processo de gestão, em especial sobre seu processo decisório. Dessa forma, percebe-se que a racionalidade e objetividade que caracterizavam o processo de decisão dessa área organizacional cedem espaço para variáveis mais sutis e subjetivas, de cunho político, social, cognitivo, perceptivo, interpretativo e narrativo (MILBURN; BILLINGS, 1976; SIMON, 1979; MOTTA, 1988; BATEMAN; ZEITHAML, 1989; VERGARA, 1991; PILLOTTO, 2003).

Verifica-se, também, que a origem dessas variáveis subjetivas organizacionais está fundamentada na cultura da organização, constituída com base em símbolos, narrativas, linguagem, mitos, entre outros, que permeia o tecido da organização e manifesta-se em todas as ações, seja 
no âmbito individual, seja coletivo (VAUGHN, 1995; STRATI, 1998). São, em especial, as relações sociais e de poder que contribuem ativamente para construir e reconstruir a realidade organizacional por meio de valores, objetivos e crenças que são compartilhadas por indivíduos associados com base em similitude de seus interesses pessoais, alinhados ou não com os interesses organizacionais.

Os processos de decisão da área de P\&D referem-se à escolha, entre uma série de alternativas, a fim de organizar os recursos alocados àquela unidade organizacional e disponibilizados para a consecução dos objetivos organizacionais. Entende-se que, pela importância dessa decisão, é possível que esteja mais suscetível à manifestação da influência das variáveis culturais visando interferir nessa escolha exercida pelo gestor. Destarte, autores como Mostaghimi (2001), Trull (1966), Schwenk (1984), Zhu e Weyant (2003) e Castellacci (2008) sugerem que a subjetividade que caracteriza as informações decorrentes da interação apresenta o potencial de mudar o posicionamento do decisor e consequentemente alterar o teor das decisões organizacionais.

O presente trabalho, construído como estudo de caso único, procura analisar como a interpretação simbólica das pessoas alocadas na unidade de P\&D, da empresa de base tecnológica Beta, que atua no segmento químico e localiza-se na Região Metropolitana de Porto Alegre, no sul do Brasil, influencia a decisão acerca da forma de realização das atividades de pesquisa tecnológica. Pela característica específica do estudo proposto, foi utilizado o método de análise de narrativas, que permite ao pesquisador interpretar as características dos depoimentos das pessoas entrevistadas.

Inicialmente, serão apresentadas as bases conceituais relativas aos temas abordados visando facultar a compreensão da linha interpretativa adotada pelo pesquisador, além de suscitar questões acerca do referido assunto, de alto grau de complexidade e subjetividade. Na sequência, será caracterizada a organização que foi o objeto deste estudo e detalhado o método de pesquisa. A análise dos resultados e as considerações finais completam a estrutura deste trabalho. 


\section{INOVAÇÃO E P\&D}

No início do século passado, surgiram os primeiros estudos com foco em inovação. O pensador alemão Schumpeter (1982), considerado precursor no tema de inovação, afirmou que a sobrevivência e o lucro extraordinário são reservados apenas para o empreendedor inovador, procurando demonstrar a importância da inovação para a constituição do diferencial competitivo. Seus estudos influenciaram pesquisadores, que aprofundaram o tema de inovação, desenvolvendo, inclusive, abordagens com foco em gestão de processos organizacionais (CHRISTENSEN, 2002; KIM; MAUBORGNE, 2005; LIMA et al., 2009; BARBIERI, 2010; FERRARESI et al., 2012; GOMES; KRUGLIANSKAS; SCHERER, 2012; OZKAYA et al., 2015). Essa ampliação do conceito original propicia a reflexão sobre novas formas de organizar os recursos e de tomar decisões à luz da complexidade presente tanto no ambiente externo como interno.

Percepção similar é apresentada por Tidd, Bessant e Pavitt (1997), Miller e Morris (1998), Kim e Mauborgne (2005), Coral e Geisler (2008), Tálamo e Carvalho (2010) e Silva, Bagno e Salerno (2014) por entenderem que o desenvolvimento de novos produtos representa uma competência importante em virtude do ambiente externo permanentemente em mudança, que, dessa forma, oferece oportunidades para criar o novo, surpreender o mercado e assumir novas posições. Como exemplo, pode ser destacado o conjunto de alterações em legislação ambiental em vários países, expressa pela família de normas ISO 14001 (BARBIERI, 2012; OZKAYA et al., 2015), tanto nos países mais desenvolvidos como nos emergentes, que ao mesmo tempo que cria novos marcos regulatórios concernentes a limites de emissão de poluentes, também oferece oportunidades de avanço tecnológico.

Miller e Morris (1998) aprofundam a reflexão sobre o modelo de negócios baseados em inovação e identificam três dimensões teóricas nas quais os mesmos se estruturam, a saber, economia, aprendizagem e gestão. A dimensão econômica caracteriza-se pela mudança da economia industrial para a economia do conhecimento. A aprendizagem, por sua vez, é o processo central para a criação de conhecimento e geração de inovações. Por fim, a gestão define as estruturas organizacionais e os meios pelos quais a inovação e as demais atividades de uma organização são realizadas.

Chaharbaghi e Newman (1996) verificam que o termo "inovação" é também empregado para descrever o processo de mudança que a adoção de novos procedimentos ou produtos provoca no indivíduo. Dessa forma, a inovação passa a fazer parte do repertório cognitivo e comportamental da pessoa, mas pode, também, consistir de uma ideia, prática ou artefato material que foi inventado ou é visto (interpretado) como novo, independente de sua adoção. Autores classificam a inovação com base em foco, em quatro tipos distintos: a) no produto ou no serviço; b) no processo de produção; c) na estrutura organizacional e d) nas pessoas.

Do ponto de vista da gestão e com os olhos voltados para o mercado, Westwood e Sekine (1988) definem a inovação como o processo pelo qual às vezes as invenções são transformadas em produtos ou sistemas economicamente sustentáveis. A sustentabilidade econômica do produto novo também está vinculada diretamente ao conceito de utilidade destacado por Stokes (2005), ao apresentar o Quadrante de Pasteur, fundamentado em pesquisa básica inspirada na sua utilização, ressaltando quatro questões conceituais relacionadas à pesquisa: (i) caracterização da pesquisa, (ii) objetivos que devem ser levados em conta, (iii) possibilidade de redução das duas dimensões a uma e (iv) tempo até a aplicação.

A abordagem de Stokes (2005) é complementada por O'Connor e Ayers (2005), que destacaram três etapas no processo de pesquisa e desenvolvimento de produtos novos para o 
mercado: (a) descoberta, centrada em conceito e composta pelas atividades de pesquisa básica, pesquisa interna e pesquisa externa por meio de licenciamento, aquisição ou investimento; (b) incubação, focada em experimentação e segmentada em atividades como a realização de testes técnicos, testes de mercado, criação com base no mercado, alinhamento estratégico; (c) aceleração, que visa à comercialização do produto no mercado e se caracteriza por três etapas, a saber, definição do foco, avaliação da resposta do mercado e investimento na fabricação do produto.

Para Rodney (2000) e Pinsky, Dias e Kruglianskas (2013), existem três grandes categorias de inovação, que são (i) a gestão estratégica inovativa para enfrentar as mudanças ambientais, (ii) a gestão de iniciativas de mudança de caráter inovador e (iii) a inovação através de criação e aplicação do conhecimento. Dentro de cada uma dessas categorias, a inovação é segmentada, na literatura tradicional, em inovação incremental e disruptiva, e Rodney (2000) propõe mais uma: a inovação relacionada ao conhecimento. Essa inclusão decorre do entendimento do autor de que a construção do conhecimento inclui a criação e reconhecimento do conhecimento que é socialmente construído. Dessa forma, as organizações são inovativas quando permitem que os novos conhecimentos sejam reconhecidos e aplicados, tanto em processos como em produtos.

Chaharbaghi e Newman (1996), Coral e Geisler (2008), Baregheh, Rowley e Sambrook (2009) e Ferraresi et al. (2012) argumentam que, ao tratar o trabalho como socialmente construído e a atividade de inovação como a aprendizagem integrada, as organizações podem criar novo conhecimento, modelos e ferramentas e adquirir novas experiências para alcançar resultados que almejam e precisam para sua sobrevivência e crescimento. A pesquisa realizada por Chaharbaghi e Newman (1996) demonstra a forma pela qual os diferentes tipos de indivíduos e de aprendizagem podem contribuir para o processo de inovação organizacional.

Essa integração, para vários autores, como Boath, Hess e Munch (1996), Westwood e Sekine (1998) e Christensen (2002), não necessariamente implica interação intraorganizacional, expandindo o conceito para o desenvolvimento de relações e parcerias, em atividades de P\&D, entre as organizações, em diferentes formas de arranjos e acordos. Nesse sentido, Harris et al. (1996), Tálamo e Carvalho (2010) e Ferraresi et al. (2012) analisam o processo de externalização de atividades em P\&D e constatam que, sob pressão para atingir maiores índices de produtividade, os gestores das áreas de P\&D são obrigados a repassar algumas das atividades de P\&D interno para instituições externas. Maior produtividade significa fazer cada vez mais com cada vez menos recursos - menos pessoas, menos equipamentos, menos dinheiro-, mas conseguindo realizar maior volume de trabalho com menos defeitos e em menor tempo possível. A solução encontrada é a externalização de P\&D, o que, no entanto, pode implicar riscos de dependência e novas vulnerabilidades.

Por esse motivo, recomenda-se que a decisão de externalizar P\&D seja baseada nas seguintes variáveis: a centralidade e importância da pesquisa para a organização, o papel estratégico da competência que provêm da pesquisa e o valor agregado da tecnologia resultante da pesquisa. Boath, Hess e Munch (1996), Tálamo e Carvalho (2010) e Ferraresi et al. (2012) corroboram essa constatação ao destacar como principais vantagens de externalização de P\&D o uso apropriado de recursos flexíveis e mais eficientes, proporcionando a redução de custos. Defendem que a empresa deve focar os esforços de P\&D interno em pesquisas de produtos estratégicos e centrais, externalizando os demais desenvolvimentos, o que reduz tanto o risco como o custo.

As teorias de aprendizagem, que a definem como construto social, com destaque para autores como Brown e Duguid (2001), Coral e Geisler (2008), Ferraresi et al. (2012) e Ozkaya et al. (2015), respaldam essa posição por argumentarem que o conhecimento representa um dos ativos mais valiosos da organização, principalmente quando este vier a contribuir para agregar ao 
valor de produtos estratégicos e centrais da empresa. Para Pawlowsky (2001) e Floriani, Beuren e Machado (2013), a aprendizagem organizacional na ciência de gestão, inovação, crescimento e ganhos de produtividade não resulta da separação de tarefas dentro do processo operacional intensivo em conhecimento, mas da integração e combinação do conhecimento com o objetivo de desenvolver novas ideias e novas soluções. Boerner, Macher e Teece (2001) argumentam que aprendizagem por meio de tentativa e erro pode ser um fator importante na determinação do sucesso da firma face à incerteza, desde que haja acompanhamento histórico dos registros dos resultados do processo. Mas a aprendizagem é um processo individual, conforme evidenciam Maier, Prange e Rosenstiel (2001), Kim (1993), Antonello (2007), Antonello e Godoy (2007), e resulta de uma experiência em decorrência da relação instrumental e social, tema explorado por Easterby-Smith, Burgoyne e Araujo (2001), para os quais a aprendizagem organizacional representa um processo técnico, um processo social e, também, um processo político. Já para Kim (1993), a aprendizagem ocorre na interação entre o indivíduo e o meio social. A aprendizagem com base na relação social é efetiva pela constatação de que as pessoas aprendem melhor a partir de modelos simbólicos inscritos no tecido social. Fear (2001) agrega ao debate ao afirmar que a aprendizagem organizacional depende da sua evolução histórica, e Weick e Westkey (2004) examinaram a aprendizagem organizacional em três subsistemas culturais: a linguagem, os artefatos e as rotinas de ação.

A revisão das vertentes teóricas mais relevantes facultou evidenciar a complexidade do ambiente organizacional da área de P\&D. Destacaram-se, nesse sentido, os textos que retratam a riqueza da dimensão subjetiva que subjaz ao aparente da realidade objetiva, o que suscita a necessidade de completar a abordagem com a revisão de conceitos relativos à análise de subjetividade presente na organização.

\section{A REPRESENTAÇÃO DA REALIDADE ORGANIZACIONAL À LUZ DO PARADIGMA INTERPRETATIVISTA}

Concebido originalmente como um processo de etapas sequenciais que visa construir a solução mais adequada para um determinado problema, o conceito do processo decisório evoluiu gradativamente em termos de complexidade e abrangência em consequência do reconhecimento da influência das variáveis subjetivas sobre o decisor no ambiente organizacional. Do esforço empreendido pelos pesquisadores, no início do século passado, para mapear, identificar e padronizar as variáveis objetivas e os fatores percebidos como centrais no processo de tomada de decisão, por meio de ferramentas tecnológicas mais ou menos avançadas, em cada período temporal, a subjetividade manifestada no processo decisório exigiu um redirecionamento de foco de pesquisa e mudança do processo de análise.

Trull (1966) constata que o processo decisório é tratado na literatura tradicional como uma sequência de etapas multifatoriais que visa solucionar um determinado problema condicionado a um conjunto de restrições. Dentro desse conceito se presume que as organizações se fundamentam em comportamento racional para conceber as soluções específicas e que o conhecimento dos fatores intervenientes (tanto internos como externos) é conhecido ou é passível de ser assimilado. Essa abordagem permite o entendimento de que é possível estruturar o processo decisório com o auxílio de ferramentas de informática, dispensando-lhe tratamento de cunho estatístico e matemático.

Em vista da intensa interação entre as pessoas no ambiente organizacional, Buttle 
(1994) conclui que a comunicação representa o locus de processos através do qual as pessoas cocriam, administram e transformam a realidade social da qual elas mesmas fazem parte. Mais do que a mera coorientação na direção de um conjunto comum de significados referenciais, as pessoas interpretam as ações e discursos de outros e coordenam suas próprias ações de acordo com o resultado dessa interpretação. Esse processo interpretativo e coordenado produz a realidade social dentro da qual a pessoa se encontra inserida.

No entanto todo processo possui uma estrutura visível e outra oculta, seja fazendo parte da interação, diálogo, planejamento ou negociação. Quando as pessoas se tornam cientes dessas estruturas de interação e do discurso que estas provêm, a linguagem assume papel central para formar a realidade ensejada por meio de relações com outras pessoas e o mundo (BUNDERSON; SUTCLIFFE, 1995). O desenvolvimento pessoal e organizacional exige novas formas de relacionamento entre as pessoas e destas com o ambiente. Para que as pessoas consigam atingir melhor desempenho, elas necessitam de novos argumentos sobre o mundo, o ambiente e a vida em si, estruturando a própria identidade, como também a identidade organizacional (HANSSON, 2002).

Symon e Clegg (2005) consideram que a identidade é negociada e construída com base na interação entre os atores sociais e investigam através de sua pesquisa por que determinadas identidades são invocadas em específicos contextos, evidenciando que a identidade socialmente construída exerce funções políticas, o que se torna relevante em momentos de mudança tecnológica. Bernstein (2005) também constata que as identidades estão disponíveis estrategicamente como uma forma de ação coletiva para mudar as instituições; para influenciar a mudança da cultura dominante, suas categorias e valores, suas políticas, estruturas e até mesmo os próprios participantes. Dessa forma a expressão da identidade pode representar uma posição de conflito e disposição para a mudança. Examinar como os grupos são representados por meio de linguagem e imagens possibilita explicar como as crenças institucionalizadas são construídas.

No entanto, a interpretação dos eventos organizacionais é diretamente dependente de sua percepção, que é seletiva, conforme destacaram Ariely e Carmon (2000), permitindo-Ihes afirmar que as pessoas sintetizam, avaliam e internalizam as experiências. Os autores constataram que não se trata de uma simples integração dos componentes isolados dos eventos percebidos, mas tendem a focar apenas alguns aspectos específicos dos eventos (características Gestalt). Esses aspectos incluem o grau de intensidade do prazer da experiência que os aspectos percebidos causam. Dessa forma Ariely e Carmon (2000) evidenciam que os aspectos observáveis devem apresentar efeitos de relevante interesse para os indivíduos para serem notados, registrados e internalizados.

Também Waller, Huber e Glick (1995) e Bunderson e Sutcliffe (1995) verificaram que o teor das experiências funcionais delimita a percepção, ou seja, torna a percepção seletiva, de executivos e gestores, na condução das organizações, não em relação ao ambiente, mas na forma de perceber as mudanças que exercem influência sobre o resultado organizacional. A pesquisa dos autores demonstrou que a percepção seletiva funcional que resulta de processos de desenvolvimento condicionado ou esquemático é provavelmente maior para os gestores operacionais do que para os executivos dos postos mais elevados dentro da organização.

Entende-se que o ambiente organizacional assume uma configuração quando a história da organização, suas narrativas, símbolos e mitos passam a apresentar significados e valores externalizados em práticas, rotinas e processos, facultando a análise compreensiva de situações e de ameaças percebidas, independentemente do seu potencial de concretização. A tomada de decisão representa um dos processos organizacionais em que a manifestação da interpretação simbólica do universo organizacional influencia efetivamente o resultado final. 


\section{PROCESSO DECISÓRIO DENTRO DO AMBIENTE OR- GANIZACIONAL}

Segundo a teoria clássica da administração, a organização possuía a capacidade de maximizar os resultados por pautar a sua atuação em racionalidade plena. Essa interpretação foi contestada por Simon (1979), com base na constatação de que o indivíduo era incapaz de coletar e processar todas as informações necessárias para a tomada de decisão no âmbito organizacional. Essa percepção da impossibilidade de alcance da racionalidade plena foi corroborada, anos mais tarde (MARCH; SIMON, 1981), com base em três observações: (i) a incompletude e imperfeição das informações coletadas; (ii) a dificuldade em prever ex ante as consequências da decisão tomada ou ação perpetrada; e (iii) a impossibilidade de identificar todas as alternativas possíveis de escolha, pelas restrições de ordem física e biológica. De forma complementar vale destacar, ainda, a relevância da dimensão política que está subjacente ao próprio conceito da organização (ARROW, 1974; MORGAN, 1996), decorrente da interpretação da ação coletiva como meio de poder, facultando, dessa forma, a realização dos valores dos indivíduos que integram os grupos sociais que constituem o tecido organizacional.

O processo decisório passou por diversas modificações, notadamente ao longo do último século. A suposta racionalidade subjacente e estruturante, que o caracterizava originalmente, no início do século passado (TRULL, 1966), foi desconstruída, em decorrência da influência da realidade percebida e interpretada, com nuances de crescente complexidade, obrigando os decisores a reconhecer a relevância de variáveis subjetivas para a tomada de decisão. Nessa perspectiva, faz-se mister reconhecer a contribuição de diversos pesquisadores, com destaque para Keeney e Raiffa (1976), Brans e Vincke (1985) e Steuer (1986), para aprimorar o processo de tomada de decisão, tanto na identificação de variáveis objetivas, com emprego de diversas ferramentas tecnológicas, como no reconhecimento dos limites da dimensão objetiva, sugerindo a necessidade de incluir variáveis de natureza subjetiva. Dessa forma, foi possível para pesquisadores, como Simon (1979), que destacou a racionalidade limitada, um novo direcionamento de foco de pesquisa e mudança do processo de análise (BRAGA, 1987; VERGARA, 1991).

Para Dean e Sharfman (1996), as restrições ambientais desempenham uma função relevante na definição de escolhas em processo decisório, reduzindo, dessa forma, a importância do processo de escolha. Os processos de decisão influenciam a efetividade decisória por meio de influência das escolhas feitas em meio a um conjunto de restrições. Para que o processo decisório resulte numa escolha efetiva, ele deverá (i) estar orientado para o alcance dos objetivos organizacionais, (ii) estar baseado sobre informações que sejam precisas e que vinculem várias alternativas aos objetivos organizacionais e (iii) estar baseado em análise e compreensão das restrições ambientais.

O primeiro elemento do modelo de decisão proposto por Dean e Sharfman (1996) é a racionalidade procedimental, definida como a extensão pela qual o processo decisório envolve o conjunto de informações relevantes à decisão e confiabilidade da análise realizada com base nessas informações para a tomada de decisão em si. O comportamento político é destacado como um aspecto do processo de decisão organizacional e se apoia em duas premissas: (i) indivíduos nas organizações apresentam diferentes interesses tanto no âmbito funcional, hierárquico e profissional, como pessoal; (ii) indivíduos dentro das organizações tentam influenciar os resultados das decisões com o objetivo de atender a seus próprios interesses e para isso se utilizam de um amplo leque de técnicas de cunho político, conforme destacou Allison (1971), ao comparar as decisões políticas com as de grandes corporações. 
Milburn e Billings (1976) definem o processo decisório como um processo constituído de múltiplos estágios, nos quais devem ser inicialmente identificados os problemas, vinculados às dimensões individuais ou coletivas, com consequente busca e identificação de alternativas e consequências das escolhas; e finalizado com a implementação das referidas escolhas e avaliação de seus resultados, com o objetivo de verificar se o problema foi eliminado. Dessa forma a definição do problema é o resultado do processo social, psicológico e político. Constata-se que a tomada de decisão envolve tipos diferentes de incertezas e de riscos, sendo que as diferenças de percepção tanto de incertezas como de riscos levam a diferentes processos de busca de alternativas de escolhas.

Howard (1984) classifica decisões em três níveis, rotineiras, táticas e estratégicas, e destaca que as decisões rotineiras se diferenciam das decisões estratégicas em complexidade, maiores implicações políticas dentro da organização, além de amplitude espacial e temporal. Realizando pesquisa quantitativa com 69 executivos norte-americanos, Hitt e Tyler (1991) concluíram que o processo decisório é, simultaneamente, racional e intuitivo. De forma mais completa, Eisenhardt e Zbaracki (1992) retratam as organizações como sistemas políticos dentro dos quais os tomadores de decisões possuem objetivos parcialmente conflitantes, a capacidade cognitiva limitada e se fundamentam tanto em variáveis racionais como políticas. A dimensão política no processo decisório se manifesta pelo fato de que os gestores mais poderosos tomam a decisão, ao passo que a dimensão racional se evidencia pelas etapas racionais de coleta de informações para a tomada de decisão.

As variáveis contextuais e situacionais desempenham um papel importante na percepção tanto de incerteza como de risco e influenciam a tomada de decisão. No entanto essa constatação contradiz, de certa forma, o modelo tradicional de tomada de decisão que se baseia em utilidade esperada, de caráter mais subjetivo, em que o indivíduo escolhe a alternativa que apresenta (na percepção dele) maior utilidade esperada. Ao vincular as duas abordagens teóricas, pode-se afirmar que a decisão ótima procura encontrar um equilíbrio entre o valor esperado de utilidade ao mesmo tempo que minimiza o risco e incerteza. $O$ fator tempo também exerce influência sobre a tomada de decisão, a partir do seu vínculo com a incerteza e com o risco, no tocante ao período temporal no qual tanto a incerteza como o risco tendem a se realizar (MILBURN; BILLINGS, 1976).

O’Dell (1992) estudou o processo de tomada de decisão por consenso e identificou fatores que devem ser considerados e tratados no referido processo decisório. O primeiro deles se refere à experiência profissional e ao nível de maturidade das pessoas que fazem parte do grupo. Normalmente as opiniões e percepções de pessoas com mais experiência e mais alta faixa etária apresentam maior influência na escolha das alternativas à decisão.

A dimensão política se destaca no processo decisório apoiada em relações de poder com o objetivo de obter resultados favoráveis em situações que implicam escolhas em meio à incerteza, falta de consenso, e também se encontra refletida em esforços de grupos interessados, para influenciar decisões que afetam ou possam vir a afetar suas posições nas organizações. Sob o mesmo enfoque, Dean e Sharfman (1996) destacam que a efetividade nas decisões organizacionais está alinhada com o atendimento dos objetivos organizacionais e constatam que o comportamento político possui o potencial para reduzir a efetividade das decisões porque implica distorção e restrição do fluxo de informações dentro da organização.

Harrison e Pelletier (2000) destacam também que a decisão é interpretada como um momento dentro do processo de avaliação de alternativas para atingir um objetivo específico, sendo que as expectativas sobre um particular curso de ação impelem o tomador de decisões 
a selecionar o curso de ação mais alinhado com os resultados esperados. Dessa forma maior parte do comportamento de quem decide pode ser explicado no contexto das decisões a serem tomadas. Essa percepção está alinhada com a constatação de Bateman e Zeithaml (1989) de que a forma e o tipo de linguagem utilizada (os termos e palavras específicas) na apresentação das informações que subsidiam o processo decisório influenciam o tomador de decisões na escolha das alternativas e na própria decisão. Constatam, também, que a interpretação e forma de percepção das experiências passadas de quem decide influencia tanto a sua percepção dos eventos no presente como as tendências futuras, destacando a relevância da influência do sentido negativo ou positivo das palavras utilizadas na apresentação de dados e informações.

\section{A CONTEXTUALIZAÇÃO E CARACTERIZAÇÃO DO MÉTODO}

O estudo que foi realizado encontra amparo da opção pelo delineamento metodológico em três autores, a saber, Tull e Hawkins (1976), Yin (2005) e Bonoma (1985), pois os fatos levantados pelo estudo são contemporâneos, a pesquisa foi realizada com uma visão externa dos pesquisadores, sem envolvimento nem manipulação de quaisquer informações, com a interpretação dos dados empíricos pelo método de análise de narrativas, segundo os modelos de Czarniawska (2000) e Riessman (1993). Vale ressaltar, também, que, entre as aplicações para o estudo de caso citado por Yin (2005), neste trabalho procurou-se descrever o contexto da vida real e realizar uma avaliação descritiva, realizando a análise à luz das vertentes teóricas, de forma restrita à organização pesquisada.

As narrativas interpretadas, segundo o método indicado por Czarniawska (2000) e Riessman (1993), originaram-se a partir de quatro entrevistas não estruturadas realizadas na organização pesquisada, com as pessoas que trabalham na área de $P \& D$, sendo elas um gestor e três técnicos. Um dos técnicos está na empresa há mais de 25 anos, tendo iniciado a sua carreira na área de produção, como estagiário, e migrado, posteriormente, para área de pesquisa e desenvolvimento, sendo esta a sua primeira e única experiência organizacional. Já o gerente e os dois outros técnicos tiveram passagens anteriores em outras organizações e estão na empresa há seis anos.

Após a gravação, em áudio, as entrevistas foram transcritas 48 horas, no máximo, após a gravação. A entrevista transcrita, que, devido ao seu formato, resulta, normalmente, num texto não linear e até confuso, foi interpretada e reescrita na forma de um texto coeso, fluido, na primeira pessoa, em formato de narrativa. Na sequência, cada uma das entrevistas foi submetida à apreciação da pessoa entrevistada, para conferência, ajustes ou contribuições. Apesar de o método não ser considerado recente, ainda é tratado como inovador (CZARNIAWSKA, 2000).

Segundo Riessman (1993) e Czarniawska (2000), a narrativa pode ser interpretada como uma fala organizada acerca de um determinado evento, situação, assunto ou tema. Trata-se da forma pela qual as pessoas contam suas experiências, o que elas enfatizam ou omitem, se elas se posicionam como protagonistas ou como vítimas. É importante destacar que o relacionamento que o narrador estabelece com o ouvinte faz com que a narrativa deixe de ser apenas o ato de contar algo, passando a ser um ato de construção de uma identidade pessoal.

De certa forma, é possível afirmar que a pesquisa por meio de narrativas escritas consiste de estudo de estórias. As estórias são onipresentes, encontradas em recortes históricos, novelas de ficção, contos, autobiografias, além de outros gêneros literários. As estórias se origi- 
nam de depoimentos das pessoas sobre suas próprias histórias e sobre outras pessoas, fazendo parte de conversas cotidianas. Somado a esses depoimentos espontâneos, faz-se necessário que os pesquisadores de narrativas fomentem estórias orais sobre temas específicos com o objetivo de serem transcritas e analisadas. A pesquisa das narrativas é considerada como uma das abordagens de pesquisa social (POLKINGHORNE, 2007).

A narrativa faz parte do processo cultural em que os sistemas simbólicos criam e são criados através do discurso e é empregada em contextos diferentes para comunicar diferentes pontos de vista. Fragmentos de narrativas maiores e versões diferentes de narrativas fazem parte do discurso cotidiano das pessoas, que são, afinal de contas, seres constituídos na linguagem baseada em significados construídos para dar sentido ao mundo em que vivem. São esses significados que fazem parte da rede de conversações, constituindo um conjunto de valores, símbolos, representações, enfim, a cultura à qual acabam se integrando (BOJE, 1995; MOEN, 2006).

A literatura revisada facultou a identificação de categorias de análise, que nortearam a interpretação dos textos transcritos, visando à compreensão do sistema simbólico construído, tanto na percepção individual, tendo como pano de fundo a experiência profissional e pessoal, representando o filtro para perceber o mundo, como na percepção social, construída a partir da interação social, compartilhando valores e narrativas, com o grupo social do qual o indivíduo faz parte. As categorias de análise que nortearam a interpretação foram: (i) a percepção do processo de seleção de oportunidades de negócios, via desenvolvimento de novos produtos ou aperfeiçoamento de produtos em carteira; (ii) a influência da composição do corpo de técnicos da organização (perfil pessoal, experiências profissionais pregressas) sobre a interpretação da realidade de mercado; (iii) a representação simbólica do universo organizacional, constituída por meio da interação social; (iv) o processo decisório na área de P\&D e suas especificidades; (v) a percepção do modelo de gestão de inovação e $P \& D$, por meio de externalização (com universidades, institutos de P\&D, empresas de consultoria etc.).

Os textos foram interpretados e criados em cada palavra e frase. Por esse motivo, a contextualização da narrativa torna-se obrigatória, pois o discurso individual é construído a partir de elementos objetivos e subjetivos que o sujeito encontra no ambiente dentro do qual ele está inserido e interpreta com base nos seus próprios pressupostos, formados a partir de sua própria experiência pessoal e profissional. Esses pressupostos formam filtros, padrões de comportamento, atitudes e verdades ou inverdades, que são utilizados pelo sujeito para caracterizar determinadas situações, ou seja, servir de parâmetro de classificação da natureza da ocorrência (RIESSMAN, 1993).

Segundo Czarniawska (2000), o método de análise de narrativas é adequado para desvelar ao pesquisador os processos adotados pelo narrador para interpretar coisas, particularmente para avaliar a interpretação do indivíduo de temas subjetivos, como, por exemplo, a cultura organizacional. Cabe ao pesquisador interpretar as interpretações do narrador. No entanto, é importante lembrar que o pesquisador não tem acesso direto à experiência do outro e por esse motivo o pesquisador lida e sempre vai lidar com formas diferentes e ambíguas de representação da experiência que o outro relatará por meio de fala, texto, interação e, é claro, interpretação.

Com base nessa constatação, acredita-se que a abordagem simbólico-interpretativista constitui o método mais apropriado para compreender, por meio de análise de narrativas com os membros organizacionais, a percepção do ambiente social da organização em estudo, visando reconhecer e identificar valores, mitos, símbolos e signos por meio dos quais os membros da organização criam e recriam, através da interação, a realidade organizacional, que influencia o processo de acolhimento (ou de isolamento) do indivíduo no grupo e na organização e do grupo 
na organização. A abordagem simbólica se baseia no conceito de construção da realidade organizacional por meio da negociação de universos simbólicos e noções de pensamentos míticos que integram o dilema positivista do verdadeiro e falso (STRATI, 1998).

\section{CARACTERIZAÇÃO DO CASO ESTUDADO}

A empresa BETA foi constituída na década de 60, numa das cidades da Região Metropolitana de Porto Alegre, da iniciativa de um empreendedor nato, com exímio domínio em mecânica. Desde muito jovem, ele manifestava forte atração por máquinas e equipamentos, o que o levou a cursar e finalizar já aos 17 anos uma das escolas técnicas de referência nesta área, na cidade de Pelotas. Logo depois foi aceito na renomada Escola da Varig, em Porto Alegre, onde se aprofundou em estudos de mecânica e eletrônica aeronáutica, tornando-se especialista reconhecido dentro da empresa, nos processos de controle eletrônico de aeronaves. Essa experiência se tornou fundamental para os passos seguintes, principalmente no tocante ao processo de inovação, pesquisa e desenvolvimento, ao mesmo tempo que possibilitou o seu direcionamento para um novo desafio: a navegação marítima.

Foi a partir das oportunidades detectadas na navegação marítima que surgiu a empresa, sendo o primeiro produto concebido e comercializado o intercomunicador, de marca ICR, produzido ainda num pequeno galpão. $O$ desenvolvimento do equipamento permitiu o acesso do jovem empreendedor ao Estaleiro Só, no início do período próspero da indústria naval brasileira. Carente de soluções tecnológicas customizadas, o setor naval apresentava uma série de problemas a serem resolvidos. Um deles, que o jovem empresário conseguiu solucionar em poucos dias, era a necessidade que existia, na época, de uma pistola de sinalização (espécie de lanterna que pudesse ser apontada na direção do navio, emitindo sinais em Código Morse) com o objetivo de realizar teste no mar.

Além desse equipamento, a empresa desenvolveu e produziu equipamentos como os motores selsyn, componentes básicos na automação analógica, sistemas e navegação, giroscópios, radiogoniômetros, além do controle do sistema hidráulico do leme das embarcações, problemas técnicos que o jovem empresário teve a capacidade de interpretar como oportunidades de negócio, cunhando o lema que representou o eixo central da sua filosofia de trabalho: "é preciso sempre ter uma alternativa quando for identificada uma falha".

Dessa forma, e com a competência técnica confirmada pela série de produtos concebidos e aplicados, com sucesso, para solucionar os problemas técnicos específicos, a empresa foi convidada a participar do II Plano Nacional de Construção Naval nos anos 70. No período que se seguiu, a empresa equipou mais de 350 navios, passando a ser referência nacional no segmento.

O sucesso do empreendimento se refletiu em números. Do galpão de 25 metros quadrados e quatro colaboradores, que caracterizavam o início da empresa, nos primeiros anos da década de 70, foi construída uma organização que passou a ocupar espaço físico total de área construída de 8 mil metros quadrados, abrigando mais de 300 colaboradores, no início dos anos 80. Foi nesse momento que o destino colocou o empresário frente a um novo desafio: a falência da indústria naval nacional.

Nesse cenário, o empresário novamente demonstrou muita flexibilidade e multifuncionalidade, pois alguns anos antes, a pedido da estatal brasileira de petróleo, a Petrobras, a empresa desenvolveu e produziu uma linha de atuadores elétricos, que são os equipamentos destinados à operação automatizada de válvulas em indústrias de processo, como petróleo e saneamento. Considerado um produto muito inovador para a época, ele não chegava a ser representativo na geração do faturamento. 
No entanto, com a crise no setor naval, foi feito um investimento na linha que se tornou, a partir da década de 90, a competência central da empresa e seu carro-chefe. Nesse sentido, a empresa foi auxiliada pelo contexto econômico, baseado em abertura dos mercados, a globalização. Enquanto para muitas empresas a abertura dos mercados representou o risco, em alguns casos decretando inclusive o encerramento das operações e a falência, para outras empresas era o melhor momento para a expansão de busca de oportunidades. Foi o caso da empresa BETA, pois, com o objetivo de se tornarem mais eficientes, muitas organizações industriais investiram em automação industrial, gerando desafios para as empresas que detinham essa competência.

Visando alcançar níveis superiores de eficiência operacional e, também, de segurança ambiental, os atuadores eletromecânicos começaram a ser substituídos por equipamentos inteligentes - automáticos. Percebendo a tendência e avaliando as suas chances para se tornar referência nesse segmento, o empresário decidiu estreitar o foco de atuação e optou por abdicar de todas as demais linhas de produção, repassando-as para os funcionários, que foram incentivados a abrir suas próprias empresas.

O novo posicionamento da empresa se mostrou válido, pois a partir de conceitos modernos, sujeitos a certificações técnicas de padrão internacional, tanto em produtos finais como em testes de fabricação, a empresa consolidou a nova tecnologia e tornou-se a única fabricante brasileira do produto. Com o objetivo de confirmar o seu nível de excelência, a empresa foi certificada dez anos atrás pela ISO 9001. Além disso, foi classificada, também, como "empresa de base tecnológica" pela Financiadora de Estudos e Projetos (Finep), obtendo o apoio para o Plano de Negócios 2003/2009, com foco na internacionalização da empresa.

\section{DESCRIÇÃo E ANÁLISE DE RESULTADOS}

A pesquisa cujos resultados embasaram a elaboração deste artigo, foi realizada com o objetivo de identificar os traços culturais e suas características, cuja natureza seria analisada, $a$ posteriori, com o objetivo de compreender o processo de gestão para a inovação dentro da área organizacional mais voltada para o desenvolvimento tecnológico-P\&D. Apesar da aparente tecnicidade do objeto de estudo, essa unidade organizacional é constituída de pessoas, que pensam, têm sentimentos, receios e medos, almejam algo e buscam realização, tanto em nível pessoal como profissional.

Destarte percebeu-se a necessidade de compreender a realidade organizacional sob o ponto de vista dessas pessoas, pois apenas assim, no entendimento dos autores, seria possível avaliar a forma de gestão dessa unidade e como ela impacta na tomada de decisão quanto a externalizar (ou não) as atividades com um agente externo. A seguir serão apresentadas as evidências que emergiram a partir das narrativas, que, na percepção dos autores, refletem a prática cultural de inovação, cuja interpretação simbólica influencia os indivíduos na área de P\&D no processo de tomada de decisão.

Ao considerar que a percepção seletiva do ambiente social e organizacional apresenta o potencial de influenciar e, consequentemente, moldar o comportamento das pessoas (WEICK, 1995; MOTTA; CALDAS, 1997; VAUGHN, 1995; STRATI, 1998), julga-se importante destacar as variáveis, as quais, durante o processo de análise, representaram o universo simbólico organizacional e facultaram à direção a introdução de valores alinhados com a nova estratégia de gestão em inovação - a externalização de algumas das etapas de pesquisa e desenvolvimento.

A primeira variável que se verifica no teor das narrativas refere-se ao compartilhamento de decisões no tocante à seleção de oportunidades de negócios, via desenvolvimento de novos produtos ou aperfeiçoamento de produtos em carteira, em atendimento a solicitações de 
clientes. Todos os entrevistados, em especial os técnicos, relataram esse fato como relevante por terem a oportunidade de externar as suas opiniões, o que eles interpretam como um sinal claro da importância do papel deles dentro da organização, refletindo o teor dos textos de Strati (1998), Ariely e Carmon (2000) e Bernstein (2005). Um dos técnicos (T2) comentou: “[...] em outras empresas o técnico da área nem tem acesso ao dono e até diretoria, sendo ouvido, contribuir, dar opinião, nem pensar". Outro técnico (T1) corroborou essa afirmação, ao relatar um episódio em que o diretor da empresa descontinuou uma linha de pesquisa de um produto, depois que ele, um mero técnico, apontou uma fragilidade do projeto: "Foi uma experiência e tanto. Muito super. Tinha um monte de engenheiros no projeto e fui eu, técnico projetista, que mostrei a inviabilidade da liga, o que causaria mais cedo ou mais tarde, a ruptura e levar até à explosão."

O evento, dedicado à discussão de oportunidades de novos negócios, por meio da análise de projetos de pesquisa em curso ou demanda de clientes para o desenvolvimento ou aperfeiçoamento de produtos em carteira, ocorre com periodicidade mensal, com participação de representantes de todas as áreas organizacionais - normalmente gestores ou técnicos seniores, ou seja, formadores de opinião. Nessa reunião, segundo o gestor da área de P\&D, todos têm vez e voz:

[...] não tem distinção entre o técnico, engenheiro, financeiro, diretoria [...] todos podem e devem se manifestar. Tem que falar com propriedade, claro. Ninguém está lá para ouvir abobrinha, mas o projeto de um produto novo passa por todos os setores dentro da firma, se tu tem [...] se tu vê algo que pode prejudicar o projeto, tem que falar.

Essa atitude, de compartilhamento das decisões de investimento ou de desinvestimento em projetos de $P \& D$, em face de oportunidades comerciais que eles podem representar, com uma equipe interdisciplinar e de vários níveis hierárquicos, reflete-se simbolicamente inclusiva e cria uma relação de confiança, que conduz ao comprometimento de todos os envolvidos nas decisões. Um dos técnicos (T3) destacou:

[...] dá para ver que o diretor e demais colegas te dão valor, pelo que tu sabe. Quando tu fala, todos escutam, claro, tem que ter bala na agulha, saber do que tá falando e depois assumir o que falou. Afinal de contas, tu assina (metaforicamente falando) junto, então depois tem que ajudar para dar certo.

A relevância do envolvimento e do contrato psicológico, no ambiente organizacional, conforme é possível interpretar a partir das narrativas dos entrevistados, foi explorada por autores como Bateman e Zeithaml (1989), Bunderson e Sutcliffe (1995) e Hansson (2002), que evidenciam maiores taxas de comprometimento com os objetivos organizacionais quando os líderes estabelecem uma relação de confiança e de parceria com os liderados. Também destacam a importância do empoderamento e dos níveis de autonomia decisória para os liderados. É claro que as formas de construir a referida relação dependem da especificidade organizacional, bem como do nível intelectual dos liderados, número de pessoas envolvidas no processo, faixa etária, fatores culturais (e sociais), entre outros. Essa especificidade foi abordada na questão seguinte, que procurou capturar a percepção dos entrevistados em relação à influência da composição do corpo técnico da área de P\&D da empresa BETA sobre o processo decisório, de forma a inovar e realizar as atividades de $P \& D$.

A composição do corpo de técnicos da organização foi destacada pelos entrevistados, pois o fundador da empresa e seu filho participam diretamente do processo seletivo dos profissionais para a área de P\&D, com base em critérios cuidadosamente escolhidos, por eles, quanto ao perfil profissional e experiências anteriores. Essa prática também foi evidenciada por Motta (1988) e Dean e Sharfman (1996), nos mais diversos ambientes organizacionais, principalmente 
para os cargos nos níveis hierárquicos mais elevados. Dessa forma as pessoas selecionadas para os referidos postos-chave, com o encargo de representar os interesses da organização, além de servirem de modelo para os demais colaboradores, como formadores de opinião (HANSSON, 2002), acabam por apresentar um perfil comportamental, atitudinal e de modelo mental muito similar ao dos diretores, uma constatação compartilhada por Eisenhardt e Zbaracki (1992) e Hansson (2002). Essa similitude refere-se tanto à interpretação do ambiente externo, da mudança, como ao constante engajamento para inovar e superar os limites, não só pessoais, mas também da sua equipe.

Todos os entrevistados (gestor e os técnicos), quando solicitados para descrever a sua visão particular do ambiente externo, seja em pontos favoráveis, seja desfavoráveis, apresentam uma linha muito próxima de representação da realidade, como um mundo em mutação, e competição entre pessoas e organizações, o que reflete a percepção de Weick (1995), Waller, Huber e Glick (1995). O gestor da área de P\&D comentou:

"Nesses mais de 20 anos de mercado, o mercado mudou muito, o consumidor mudou muito. Tem cada vez mais concorrentes no mercado, e a empresa tem que se adequar. Lançar novos produtos, não dá para parar."

O técnico T3 acrescenta:

"Na água parada cria limo [risos]. No nosso caso, quem não se atualiza, não se especializa, tá fora do mercado, igual a firma, se não inova, perde o mercado."

Conforme é possível interpretar, existe um alinhamento perceptivo, entre o gestor e o técnico, quanto à necessidade de se adaptar ao mercado em permanente mudança, o que também se aplica aos profissionais. Essa realidade exige, na percepção dos entrevistados, a constante busca pela atualização e pela inovação, tanto em relações pessoais, competências, habilidades, como, no caso de empresas, de produtos, processos, serviços, atendimento, proximidade do cliente, qualidade e custo cada vez mais baixo.

Em todas as narrativas, ficou evidente a percepção dos entrevistados quanto ao destaque e à valorização dos profissionais dentro da organização, que demonstram atitudes alinhadas com essa priorização de busca pela competência técnica e profissional, tanto por meio de expertise e conhecimento prático (técnico sênior com 25 anos de empresa), como pela titulação acadêmica e experiência profissional alinhada com as habilidades consideradas centrais pela organização, confirmando as abordagens de Chaharbaghi e Newman (1996) e Stokowski (2002). O técnico T1 comentou:

[...] se tu tem a competência técnica, se posiciona bem, tem argumento e demonstra que sabe, tá com tudo para crescer aqui na firma. Ainda mais se for na área mecânica [risos] [formação e área de conhecimento do fundador]. Claro que se tu é bom no que faz, mesmo sendo do suporte, pessoal valoriza, claro. Tem que agregar.

A relevância da compatibilidade ou a similitude da formação e competência técnica com o perfil profissional dos decisores (diretores), como fator condicionante para a progressão na carreira, é percebida pelos entrevistados. O gestor destacou:

"[...] já na entrevista do processo seletivo, percebi o que eles [os diretores] queriam alguém com experiência em empresas de base tecnológica, focado em projetos e perfil de pesquisador, para servir de exemplo aos técnicos".

O teor das narrativas dos técnicos entrevistados revela que isso, de fato, ocorreu, conforme comentou o técnico T2: “O chefe [gestor] é muito parceiro, se envolve nos projetos com a 
gente, sempre dá muita dica para resolver o problema. Conhece muito, é sempre bom parar para ouvir ele falar. Sempre argumenta com muito embasamento."

Nos últimos anos, a diretoria tem compartilhado com a equipe a necessidade de adequar o processo de inovação e de $\mathrm{P} \& \mathrm{D}$ à nova realidade de mercado. Os custos se tornaram muito elevados, e o risco de rejeição de novos produtos no mercado, também. Tornou-se imprescindível inovar o processo de P\&D. Entre as alternativas, destaca-se a externalização parcial ou até total de algumas de suas atividades. Esse posicionamento foi interpretado, inicialmente, pelos técnicos da área, de forma negativa, conforme destacou o técnico T3:

"[...] o repasse de algumas das nossas atividades para serem feitas pelos bolsistas de mestrado e doutorado nas universidades, ou pelos técnicos de um instituto, nos assustou, no começo [...] como fica o nosso emprego, né? Todo mundo tem conta para pagar [...]".

No entanto, conforme pode ser interpretado a partir do comentário de técnico T1, a influência simbólica do gestor e diretoria, seja como formadores de opinião (gestor), seja pelo empoderamento, decorrente da relação de confiança constituída pela inclusão dos técnicos nas reuniões mensais, foi determinante para a mudança perceptiva do processo de externalização das atividades de P\&D. $O$ argumento central da diretoria, e compartilhado com os gestores organizacionais, é que a nova modalidade de realização das referidas atividades é essencial para o avanço dos projetos ou para situações em que a organização constata que não detém a necessária expertise. Esse fato evidencia a atuação sobre a dimensão política organizacional, conforme destacado por Milburn e Billings (1976) e Eisenhardt e Zbaracki (1992), além de representar a construção simbólica no universo organizacional, segundo as características tipificadas por Strati (1998).

Ao analisar o caso do gestor responsável pela área de P\&D, é possível afirmar que, devido às suas características de superioridade de conhecimento técnico e know-how tecnológico, representando o exemplo de profissional a ser seguido, os demais colegas entram, inicialmente, em conflito, com base em conceitos pré-concebidos acerca da modalidade de realização das atividades de P\&D (CORAL; GEISLER, 2008; OZKAYA et al., 2015). O modelo preferencial de execução interna, com garantia de trabalho a todos e poder de barganha, pela carga de conhecimento técnico, de difícil transmissão e compartilhamento, entra em choque com o novo conceito, que representa o avanço tecnológico e a modernidade, configurando o conflito de interesses baseados na interpretação dos eventos organizacionais, conforme constataram Harrison e Pelletier (2000).

A possibilidade de aprendizagem decorrente da interação foi utilizada como mais um dos argumentos a favor da externalização e foi construída com o objetivo de minimizar a resistência ao novo modelo (SILVA; BAGNO; SALERNO, 2014) decorrente das preocupações dos técnicos quanto à perda do poder baseado no conhecimento técnico, quase único, raro e de difícil imitação (BARNEY, 1991). Esse argumento foi reforçado por técnicos de "primeira linha" - alinhados ao discurso da diretoria -, pela elevação do nível de qualificação, através de contato com instituições de reconhecida base tecnológica em determinadas áreas de conhecimento.

Dessa forma, pouco a pouco, paulatinamente, os técnicos assimilavam o novo modelo de gestão de P\&D (BAREGHEH; ROWLEY; SAMBROOK, 2009). Entretanto percebe-se que a faixa etária e experiências anteriores influenciam o processo de adesão, com os profissionais mais experientes manifestando maior resistência do que seus colegas mais novos, tanto na função como na organização, decorrente de uma postura mais reflexiva, evidenciada no trecho da narrativa do técnico T3:

Eu não sou mais um guri, já passei por muita coisa e sei que a vida na firma é uma coisa e tua vida pessoal é outra. Não dá para misturar. Enquanto está tudo bem para todo mundo, 
ok, mas quando a coisa aperta, é cada um por si. Acho que hoje o modelo de parceria é válido, com serviço sobrando, mas no futuro, só Deus sabe.

Já o técnico T1, com 28 anos de idade e seis de empresa, demonstra nível de confiança mais elevado na relação com a diretoria e o gestor:

Eu sinto que posso confiar no pessoal [diretoria] quando eles falam que as parcerias são feitas para nos dar o suporte e que nós, os técnicos, é que faremos a coordenação do processo, do que faremos aqui e do que será feito por outros. Acho que vai ser melhor, é a tendência de mercado, não dá para ignorar isso.

Diversos autores, com destaque para Geertz (1989), Bateman e Zeithaml (1989), Morgan (1996), Strati (1998) e Beyer (1997), evidenciaram que a forma de liderança mais efetiva ocorre por meio de interpretação simbólica, pelo envolvimento, por meio de relações de confiança, pelo exemplo discursivo e atitudinal, alinhado com os valores pessoais e profissionais dos liderados. A imposição direta, por ordens, regras e normas, carregadas de objetividade, além de ser quase sempre precária no seu intento de representar a complexidade da realidade circundante, suscita a resistência natural da maioria dos indivíduos, que encontram formas e meios de torná-las menos efetivas (STUMPF; DUNBAR, 1991; STOKOWSKI, 2002; VAUGHN, 1995).

Quadro 1 - Categorias de análise, evidências e autores de referência

\begin{tabular}{|c|c|c|}
\hline Categorias de análise & Evidenciação & Autores de referência \\
\hline Processo decisório na área de & $\begin{array}{c}\text { Compartilhamento de decisões } \\
\text { na área de P\&D, dando oportu- } \\
\text { nidade aos técnicos para exter- } \\
\text { nar as suas opiniões, o que eles } \\
\text { interpretam como um sinal claro } \\
\text { da importância do papel deles } \\
\text { dentro da organização; simboliza } \\
\text { inclusão e cria uma relação de } \\
\text { confiança. }\end{array}$ & $\begin{array}{c}\text { Strati (1998), Ariely e Carmon } \\
\text { (2000) e Bernstein (2005) }\end{array}$ \\
& $\begin{array}{c}\text { Estabelecimento do contrato } \\
\text { psicológico dos líderes com os } \\
\text { liderados, por meio de uma rela- } \\
\text { ção de confiança e de parceria, } \\
\text { no ambiente organizacional. }\end{array}$ & $\begin{array}{c}\text { Bunderson e Sutcliffe (1995) e } \\
\text { Hansson (2002) }\end{array}$ \\
\hline Comprometimento com os obje- \\
tivos organizacionais & & \\
\hline
\end{tabular}




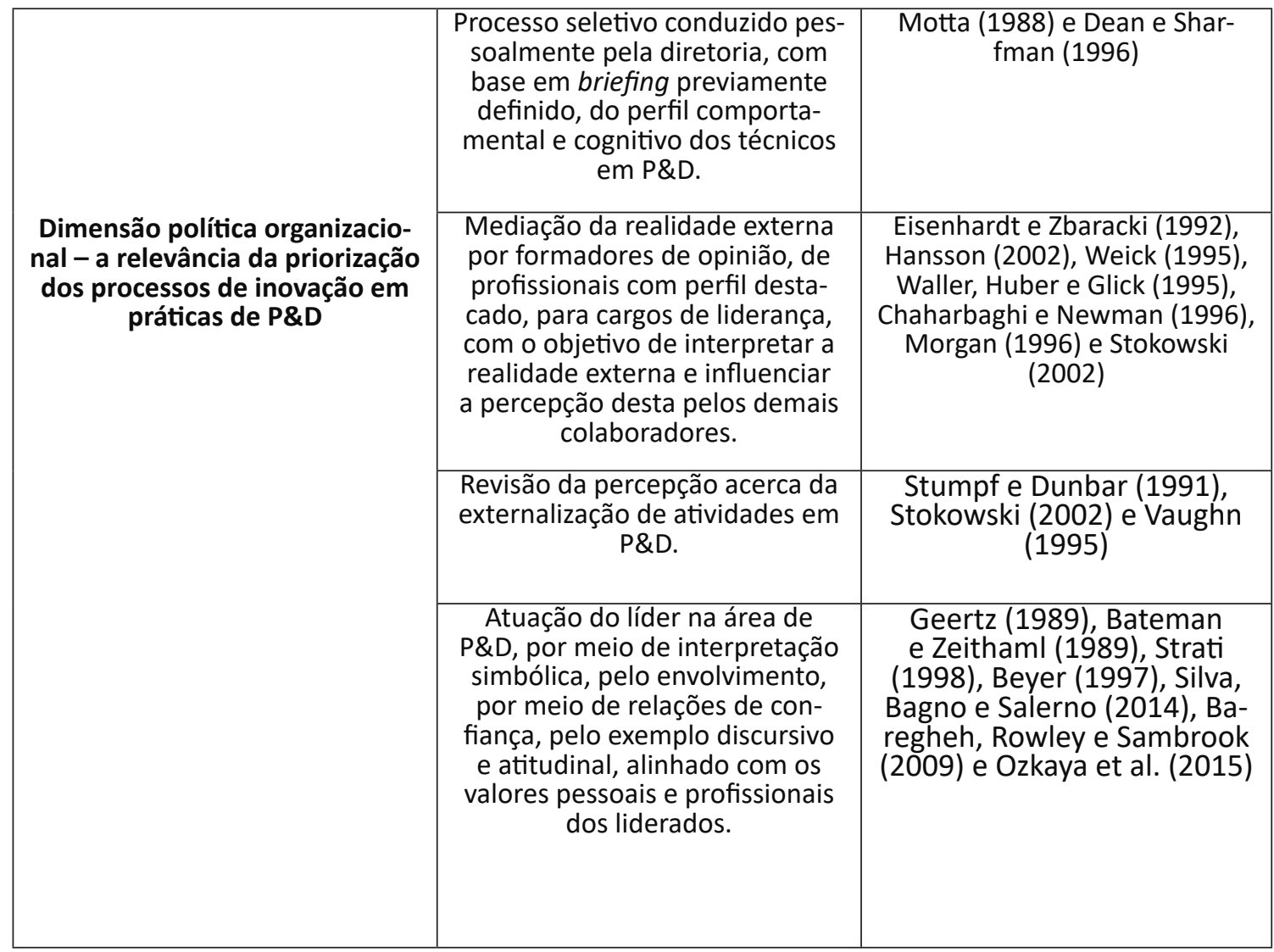

Fonte: elaborado pelos autores.

O ambiente de mercado encontra-se em permanente processo de mudança, em virtude da constante evolução social, científica e tecnológica, o que o torna complexo e multifacetado. Essa realidade exige das organizações, que desejam permanecer na operação, adaptar-se, alterando o modelo de negócio e/ou revisando a sua forma de atuar, tanto na esfera estratégica como operacional. Esse processo inicia pela interpretação e reinterpretação do ambiente externo pelos participantes do universo organizacional, o que faculta a introdução de mudanças em processos e práticas organizacionais.

Neste trabalho foram evidenciados elementos estruturantes do processo de mudança que ocorreu do setor de P\&D da empresa BETA, no tocante ao processo decisório, com base na atuação da liderança organizacional sobre o universo simbólico reinterpretado e compartilhado com os técnicos da referida unidade organizacional. O Quadro 1 sintetizou os referidos elementos do estudo, apresentando as categorias de análise, as evidências relacionadas e os autores revisados que suportam e fornecem embasamento teórico para cada uma delas. 


\section{CONSIDERAÇÕES FINAIS}

O processo decisório no âmbito organizacional representa, cada vez mais, um desafio relevante, em virtude da crescente complexidade que caracteriza tanto o ambiente externo como interno. A quantidade e a variedade de dados, informações e situações, de natureza social, tecnológica e política, entre outras, extrapola os limites da capacidade cognitiva individual, tanto no processo de sua coleta como na sua interpretação, para subsidiar o referido processo decisório. Além disso, os elementos constitutivos e estruturantes, seja de natureza endógena, seja exógena, estão em permanente processo de transformação, exigindo a constante revisão dos cenários que orientam e embasam a tomada de decisão nas organizações.

Todas as unidades organizacionais são influenciadas pela alteração das condições ambientais subjacentes ao processo de tomada de decisão, mesmo que de formas e intensidade variadas, de setor a setor, em virtude de especificidades que caracterizam a sua interação com os stakeholders. No entanto, essa situação pode se tornar particularmente crítica em unidades organizacionais que são responsáveis pela introdução, ao mercado, de novos produtos - área de P\&D.

O acirramento da competição entre as organizações no mercado nas últimas décadas exigiu a adoção de novas estratégias, tanto no Brasil como no exterior. As pesquisas apontam para a necessidade de um diferencial competitivo, a fim de assegurar a permanência da organização no mercado. Uma das alternativas que vêm sendo destacadas, com maior ênfase nas duas últimas décadas, consiste da construção da diferenciação com base em inovação. Independente da forma (produto, processo, incremental ou disruptiva, entre outras), o desenvolvimento da competência em inovação passou a ser pesquisado com maior afinco nas últimas décadas. Essa abordagem acabou originando vários estudos que analisaram desde a forma de inovar, o processo, até os fatores que obstaculizam a inovação.

No entanto, não são tão numerosos os estudos que procuram analisar a relação entre a gestão estratégica voltada para a inovação e a cultura organizacional, apesar do nexo causal existente, devido ao fato de que a inovação não ocorre pela imposição do superior hierárquico e tampouco pelo sistema de regras objetivas, normas e procedimentos. O motivo está no fato de que é o ser humano que faz a inovação acontecer e ele é um ser reflexivo, que interpreta sinais do ambiente onde está inserido, com base na percepção moldada pelas vivências intra e extraorganizacionais.

Dessa forma é possível concluir que a gestão da inovação está vinculada, na sua essência, à cultura organizacional, como foi possível verificar no caso estudado, na empresa BETA. $O$ seu universo organizacional foi construído apoiando-se no simbólico, no implícito, que faculta a percepção e interpretação da relevância da inovação para a organização, como diferencial competitivo. $\mathrm{O}$ discurso foi aliado à prática, e o tema inovação passou a fazer parte das narrativas e práticas organizacionais.

Por esse motivo, foi possível introduzir no repertório conceitual, apesar da resistência inicial, baseada em vivências anteriores e conceitos pré-concebidos, um novo modo de realizar as atividades de pesquisa e desenvolvimento - através de interação com agentes externos, por meio de externalização de tarefas, em maior ou menor grau. Técnicos seniores com notável expertise e liderança formal ou informal, dentro da estrutura organizacional, adotaram o novo posicionamento e, pelo exemplo (discursivo e atitudinal), colocaram em dúvida o modelo anterior, de realização interna, na sua integralidade, das atividades dessa unidade organizacional.

A pesquisa, estudo de caso único, foi realizada pelo método de análise de narrativas, 
permitindo o surgimento de processos, práticas, ritos, valores e discursos que transmitem e compartilham a cultura de inovação, facultando a compreensão do universo simbólico dessa área técnica, de vital importância para as organizações. Foi possível interpretar o ponto de vista dos técnicos da área quando da alteração do processo interno, que passou da execução interna para a externalização, permitindo a compreensão da abordagem adotada pela direção da empresa. Destarte, o estudo atingiu os objetivos, por conseguir evidenciar a forma sutil e implícita de mudança de valores e paradigmas constituídos, por meio de interpretação simbólica, a partir do discurso e atitudes dos formadores de opinião organizacionais.

Os autores entendem que o estudo convida para novas abordagens do tema, cada vez mais atual e presente na pauta de decisões organizacionais em virtude da necessidade de tornar as organizações mais flexíveis e com estruturas menos pesadas, facultando o desenvolvimento de competências e aumentando as chances de sucesso para concorrer nos mercados locais e externos.

\section{REFERÊNCIAS}

ALLISON, G. T. Essence of decision: explaining the Cuban missile crisis. Boston, Little Brown, 1971.

ANTONELLO, C. S. O processo de aprendizagem interníveis e o desenvolvimento de competências. Revista Brasileira de Gestão de Negócios, v. 9, n. 25, p. 39-58, 2007.

ANTONELLO, C. S.; GODOY, A. S. A encruzilhada da aprendizagem organizacional: uma visão multiparadigmática. In: ENCONTRO ANUAL DA ANPAD, 31., 2007, Rio de Janeiro. Anais... Rio de Janeiro: Anpad, 2007. p. 1-16.

ARIELY, D.; CARMON, Z. Gestalt characteristics of experience: the defining features of summarized events. Journal of Behavioral Decision Making, v. 13, n. 2, Apr./Jun. 2000.

ARROW, K. J. The limits of organization. New York: W.W. Norton. 1974.

BARBIERI, J. C. Gestão ambiental empresarial: conceitos, modelos e instrumentos. 3. ed. atual. e ampl. São Paulo: Saraiva, 2012. xviii, 358 p.

BARBIERI, J. C. et al. Inovação e sustentabilidade: novos modelos e proposições. Revista de Administração de Empresas, v. 50, n. 2, p. 146-154, 2010

BAREGHEH, A.; ROWLEY, J.; SAMBROOK, S. Towards a multidisciplinary definition of innovation. 
Management Decision, v. 47, n. 8, p. 1.323-1.339, 2009.

BARNEY, J. Firm resources and Sustained Competitive Advantage. Journal of Management, v. 17, n. 1, p. 99-120, 1991.

BATEMAN, T. S.; ZEITHAML, C. P. The psychological context of strategic decision: a model and convergent experimental findings. Strategic Management Journal, v. 10, n. 1, Jan./Feb. 1989.

BERNSTEIN, M. Identity Politics. Annual Review of Sociology, v. 31, 2005.

BEYER, J. M. et al. The selective perception of managers revisited. Academy of Management Journal, v. 40, n. 3, Jun. 1997.

BOATH, D.; HESS, P.; MUNCH, C.. Virtual R\&D: A core competency approach to outsourcing. Pharmaceutical Executive, v. 16, n. 6, Jun. 1996.

BOERNER, C.; MACHER, J. T.; TEECE, D. J. A Review and Assessment of Organizational Learning in Economic Theories. In: DIERKES, M. et al. (Org.). Organizational Learning and Knowledge. New York: Oxford, 2001. cap. 4, p. 89-117.

BOJE, D. M. Stories of the storytelling organization: A postmodern analysis of Disney as "TamaraLand". Academy of Management Journal, Aug. 1995.

BONOMA, T. V. Case Research in Marketing: Opportunities, Problems and Process. Journal of Marketing Research, v. XXII, May 1985.

BRAGA, N. O processo decisório em organizações brasileiras. Revista de Administração Pública, v, 21, n. 3, p. 35-57, 1987.

BRANS, J. P.; VINCKE, P. A preference ranking organization method, Management Science,v. 31, p. 647-656, 1985.

BROWN, J. S.; DUGUID, P. Knowledge and organization: a social-practice perspective. Organization 
Science, v. 12, n. 2, p. 198-213, Mar./Apr. 2001;

BUNDERSON, S. J.; SUTCLIFFE, K. M. Work History and selective perception: Fine-tuning what we know. Academy of Management Journal, 1995.

BUTTLE, F. A. The co-ordinated management of meaning: A case exemplar of a new consumer research technology. European Journal of Marketing, v. 28, n. 8-9, 1994.

CASTELLACCI, F. Technological paradigms, regimes and trajectories: manufacturing and service industries in a new taxonomy of sectoral patterns of innovation. Research Policy, v. 37, p. 978994, 2008.

CHAHARBAGHI; K.; NEWMAN, V.. Innovating: towards an integrated learning model. Management Decision, London, v. 34, n. 4, 1996.

CHANDLER, A. D. Organizational Capabilities and the Economic History of the Industrial Enterprise. The Journal of Economic Perspectives (1986-1998), v. 6, n. 3, Summer 1992.

CHRISTENSEN, J. F. Corporate strategy and the management of innovation and technology. Industrial and Corporate Change, v. 11, n. 2, p. 263-288, 2002.

CORAL, E.; GEISLER, L. Motivação para a inovação. In.: CORAL, E.; OGLIARI, A.; ABREU, A. F. Gestão integrada da inovação: estratégia, organização e desenvolvimento de produtos. São Paulo: Atlas, 2008.

CZARNIAWSKA, B. Anthropology and Organizational Learning. Oxford: Oxford University Press, 2000. cap. 5, p. 118-136.

DAFT, R.; WEICK, K. E. Por um modelo de organização concebido como sistema interpretativo. Revista de Administração de Empresas - RAE, v. 45, n. 4, p. 73-86, 2005.

DEAN, J. W. Jr; SHARFMAN, M. P. Does decision process matter? A study of strategic decisionmaking effectiveness. Academy of Management Journal, v. 39, n. 2, Apr 1996. 
DRUSKAT, V.; WHEELER, J. Managing from the boundary: the effective leadership of self-managing work teams. The Academy of Management Journal, v. 46, n. 4, p. 435-457, 2003.

EASTERBY-SMITH, M., BURGOYNE, J., ARAUJO, L. Aprendizagem Organizacional e Organização de Aprendizagem: desenvolvimento na teoria e na prática. São Paulo: Atlas, 2001.

EISENHARDT, K. M; ZBARACKI, M. J. Strategic decision making. Strategic Management Journal, v. 13, Winter 1992.

FAYET, E. A. Inovação: conceitos e teorias. In: FAYET, E. A. (Org.). Gerenciar a inovação: um desafio para as empresas. Curitiba: IEL. 2010.

FEAR, J. J. Thinking Historically about Organizational Learning. In: DIERKES, Meinolf et a. (Org.). Organizational Learning and Knowledge. New York: Oxford, 2001. cap.7, p. 162-190.

FERRARESI, A. A. et al. Knowledge management and strategic orientation: leveraging innovativeness and performance. Journal of Knowledge Management, v. 16, n. 5, 2012.

FLORIANI, R.; BEUREN, I. M.; MACHADO, D. D. P. N. Processo de inovação em empresas brasileiras de capital aberto. Revista de Administração da UFSM, Santa Maria, v. 6, n. 4, p. 783-802, dez. 2013.

FREZATTI, F. et al. O papel do Balanced Scorecard na Gestão da Inovação. Revista de Administração de Empresas, v. 54, n. 4, p. 381-392. 2014.

GEERTZ, C. A interpretação das culturas. Rio de Janeiro: LTC, 1989

GHEMAWAT, P. Competition and business strategy in historical perspective. Business Review, v. 76, n. 1, p. 37-74, Spring 2002.

GOMES, C. M.; KRUGLIANSKAS, I.; SCHERER, F. L. The influence of the management of information sources on the innovation performance of large and small business. International Journal of Innovation Management, v. 16, n. 2, 2012 
HANSSON, T. Leadership by Activity Theory and Professional Development by Social Construction. Systemic Practice and Action Research, v. 15, n. 5, Oct. 2002.

HARRIS, R. C; et al. The virtual R\&D laboratory. Research Technology Management, v. 39, n. 2, Mar./Apr. 1996

HARRISON, E. F.; PELLETIER, M. A. The essence of management decision. Management Decision, London, v. 38, n. 7, 2000.

HITT, M. A.; TYLER, B. B. Strategic Decision Models: Integrating Different Perspectives. Strategic Management Journal, v. 12, n. 5, Jul. 1991.

HOWARD, T. Strategic decision analysis: applied decision analysis and it's role in the strategic management process. Strategic Management Journal, v. 5, n. 2, Apr./Jun. 1984.

KAY, J. Fundamentos do sucesso empresarial: como as estratégias agregam valor. Rio de Janeiro: Campus, 1996. cap. 21, p. 365-393.

KEENEY, R. L.; RAIFFA, H. Decisions with Multiple Objectives: Performances and Value Trade-Offs. New York: Wiley, 1976.

$\mathrm{KIM}, \mathrm{D} . \mathrm{H}$. The link between individual and organizational learning. Sloan Management Review, p. 37-50, Fall 1993.

KIM, W. C.; MAUBORGNE, R. A estratégia do Oceano Azul: como criar novos mercados e tornar a concorrência irrelevante. 5. ed. Rio de Janeiro: Elsevier, 2005.

LIMA, E. et al. Foco na inovação e complementaridade em equipes de direção no desenvolvimento de novas empresas tecnológicas. Revista de Administração UFSM, Santa Maria, v. 2, n. 2, p. 343357, maio/ago. 2009

MAIER, G.; PRANGE, C.; VON ROSENSTIEL, L. Psychological Perspectives of Organizational learning. In: DIERKES, M. et al. (Org.). Organizational Learning and Knowledge. New York: Oxford, 2001. cap. 1, p. 14-34. 
MARCH, J. G.; SIMON, H. A. Teoria das organizações. 5. ed.. Rio de Janeiro: Fundação Getúlio Vargas. 1981.

MCNULTY, T.; WHITTINGTON, R. Putting the Marketing into R\&D. Marketing Inteligence \& Planning, v. 10, n. 9, 1992.

MILBURN, T. W; BILLINGS, R. S. Decision-making perspectives from psychology. The American, v. 20, n. 1, Sep./Oct. 1976.

MILLER, W. L.; MORRIS, L. 4th Generation R\&D: Managing Knowledge, Technology, and Innovation. Nova lorque: John Wiley \& Sons, Inc., 1998.

MOEN, T. Reflections on the Narrative Research Approach. International Journal of Qualitative Methods, n. 4, Dec. 2006.

MORGAN, G. Imagens da organização. São Paulo: Atlas. 1996.

MOSTAGHIMI, M. Information collection strategic design in experts-assisted decision making paradigm. Group Decision and Negotiation, v. 10, n. 5, Sept. 2001.

MOTTA, F. C.; CALDAS, M. Cultura organizacional e cultura brasileira. São Paulo: Atlas, 1997.

MOTTA, P. R. Razão e intuição: recuperando o ilógico na teoria da decisão gerencial. Revista de Administração Pública, Rio de Janeiro, v. 22, n. 3, p. 77-94, Jul./Set. 1988.

O'CONNOR, G. C.; AYERS, Alan D. Building a Radical Innovation Competency. Research Technology Management, v. 48, n. 1, Jan./Feb. 2005.

O'DELL, W. F. Effective business decision making. Small Business Reports, v. 17, n. 3, Mar. 1992.

OZKAYA, H. E. et al. Market orientation, knowledge competence, and innovation. International Journal of Research in Marketing, 2015. 
PAWLOWSKY, P. The treatment of organizational learning in management science. In: DIERKES, M. et al. (Org.). Organizational Learning and Knowledge. New York: Oxford, 2001. cap. 3, p. 6188.

PILLOTTO, S. S. D. Gestão e conhecimento sensível na contemporaneidade. Florianópolis: Ed. da UFSC, 2006.

PINSKY, V. C.; DIAS, J. L.; KRUGLIANSKAS, I. Gestão estratégica da sustentabilidade e inovação. Revista de Administração da UFSM, Santa Maria, v. 6, n. 3, p. 465-480, set. 2013.

PLENTZ, N. D.; BERNARDES, M. M. S.; FRAGA, P. G. R. Sistema de indicadores de inovação, competitividade e design para empresas desenvolvedoras de produtos. Porto Alegre: Marca Visual, 2015.

POLKINGHORNE, D. E. Validity issues in narrative research. Qualitative Inquiry, v. 13, n. 4, p. 471486, 2007.

PRAHALAD, C. K., HAMEL, Gary. Strategy as a field of study: Why search for a new paradigm? Strategic Management Journal, v. 15, p. 1-16, 1994.

RIESSMAN, C. K. Narrative analysis. London: SAGE, 1993.

RODNEY, M. A. Knowledge management as a catalyst for innovation within organizations: a qualitative study. Knowledge and Process Management, v. 7, n. 4, Oct./Dec. 2000.

SASSENBERG, K.; BOOS, M.; RABUNG, S. Attitude change in face-to-face and computer-mediated communication: private self-awareness as mediator and moderator. European Journal of Social Psychology, v. 35, p. 361-374, 2005.

SCHUMPETER, J. A. Teoria do desenvolvimento econômico: uma investigação sobre lucros, capital, juro e o ciclo econômico. São Paulo: Abril Cultural, 1982.

SCHWENK, C. R. Cognitive Simplification Processes in Strategic Decision-making. Strategic 
Management Journal, v. 5, n. 2, Apr./Jun. 1984.

SILVA, D. O.; BAGNO, R. B.; SALERNO, M. S. Modelos para a gestão da inovação: revisão e análise da literatura. Production, v. 24, n. 2, p. 477-490, abr./jun. 2014.

SIMON, H. A. Comportamento administrativo. 3. ed. Rio de Janeiro: FGV, 1979.

STEUER, R. E. Multiple criteria optimization: theory, computation and application. New York: Wiley, 1986.

STOKES, D. E. O Quadrante de Pasteur: a ciência básica e a inovação tecnológica. Campinas: Editora Unicamp, 2005.

STOKOWSKI, P. A. Languages of place and discourses of power: Constructing new senses of place. Journal of Leisure Research, v. 34, n. 4, 2002.

STRATI, A. Organizational symbolism as a social construction: A perspective from the Sociology of Knowledge. Human Relations, v. 51, n. 11, Nov. 1998.

STUMPF, S. A.; DUNBAR, R. L. M. The effects of personality type on choices made in strategic decision situations. Decision Sciences, v. 22, n. 5, Nov./Dec. 1991.

SYMON, G.; CLEGG, C. Constructing identity and participation during technological change. Human Relations, v. 58, n. 9, Sept. 2005.

TÁlAMO, J. R.; CARVALHO, M. M. Redes de cooperação com foco em inovação: um estudo exploratório. Gestão \& Produção. v. 17, n. 4, p. 747- 760, 2010.

TIDD, J.; BESSANT, J.; PAVITT, K. Managing innovation. West Sussex: John Willey \& Sons, 1997.

TRULL, S. G. Some factors involved in determining total decision success. Management Science, 1966. 
TULL, D. S.; HAWKINS, D. I. Marketing Research, Meaning, Measurement and Method. London: Macmillan Publishing Co., Inc., 1976

VAUGHN, M. A. Organization Symbols: An Analysis of their types and functions in a reborn organization. Management Communication Quarterly: McQ, Nov. 1995.

VERGARA, S. C. Razão e intuição na tomada de decisão: uma abordagem exploratória. Revista de Administração Pública, v. 25, n. 3, p. 120-138, 1991.

WALLER, M. J.; HUBER, G. O.; GLICK, W. H. Functional background as a determinant of executives selective perception. Academy of Management Journal. Briarcliff Manor, v. 38, n. 4, Aug. 1995.

WEICK, K. E. Sensemaking in organization. London: Sage, 1995.

WEICK, K. E.; WESTLEY, F. Aprendizagem organizacional: confirmando um oxímoro. In: CLEGG, S. R.; HARDY, C.; NORD, W. R. (Org.). Handbook de estudos organizacionais. São Paulo: Atlas, 2004. p. 361-388.

WESTWOOD, A. R. C.; SEKINE, Y. Fostering Creativity and Innovation in an Industrial R\&D Laboratory. Research Technology Management, v. 31, n. 4, Jul./Aug. 1988.

YIN, R. Estudo de caso: planejamento e métodos. Porto Alegre: Bookman, 2005.

ZHU, K.; WEYANT, J. P. Strategic decisions of new technology adoption under asymmetric information: a game-theoretic model. Decision Sciences, v. 34, n. 4, p. 643-675, 2003. 